\title{
Urologic Surgeon
}

National Cancer Institute

\section{Source}

National Cancer Institute. Urologic Surgeon. NCI Thesaurus. Code C17842.

A surgeon who specializes in treatment of diseases and disorders of the genitourinary tract. 